\title{
Occupational Dermatoses from One-Component Epoxy Coatings Containing a Modified Polyamine Hardener
}

\author{
Kozo YOKOTA*, Yasushi JOHYAMA and Kyohei YAMAGUCHI \\ Matsushita Science Center of Industrial Hygiene, 7-6 Tonoshima-cho, Kadoma, Osaka 571-0045, Japan \\ Received November 30, 1999 and accepted April 3, 2000
}

\begin{abstract}
In an electronics plant, 2 one-component epoxy coatings containing a modified polyamine hardener were used as covering materials for protecting important information on police radio circuit boards. The resinous parts of the coatings consisted of epoxy resins based on diglycidyl ether of bisphenol F. The hardener was a dimethylaminopropylamine (DMAPA)-epoxy adduct and contained about $0.16 \%$ free DMAPA. Of 105 workers, $17(16 \%)$ were diagnosed to have workrelated dermatitis but were not patch tested. The hands were the commonly affected region (13 out of 17 cases). The latent period of dermatitis was very short (mean 21.5 days). The work-related dermatoses were closely related to the type of work and working periods. In the present study, hand protection and the introduction of automation have been demonstrated to be useful for the prevention of epoxy coating dermatitis.
\end{abstract}

Key words: Amine-epoxy adducts, Automation, Contact dermatitis, Diglycidyl ether of bisphenol F, Individual protective devices, One-component epoxy coatings

\section{Introduction}

Epoxy resins are widely used in adhesives, coatings, materials for molds and composites, and encapsulation. Epoxy resin compounds include a large number of sensitizing chemicals such as epoxy resins, hardeners (curing agents), and reactive diluents ${ }^{1-3)}$. Allergic and irritant contact dermatitis are often caused by epoxy resin compounds. Epoxy resins based on diglycidyl ether of bisphenol A are the most common causes of occupational allergic contact dermatitis. Epoxy hardeners also include strong allergens. Low molecular weight aliphatic and aromatic polyamines are the best known contact sensitizers ${ }^{4}$. To overcome these problems, many kinds of modified polyamines have been recently developed and used as hardeners, including polyamide and amine-epoxy adducts. Polyamides are prepared by combining aliphatic amines with fatty acids. Amine-epoxy adducts are formed in reaction between epoxy resin and an excess of polyamine. On the other hand,

*To whom correspondence should be addressed. anhydride hardeners rarely cause delayed contact allergy, but are well known occupational respiratory allergens ${ }^{5}$. Other substances responsible for contact allergy are mainly reactive diluents, used to reduce viscosity and improve polymerization. This is a report on occupational dermatoses caused by 2 one-component epoxy coatings containing diglycidyl ether of bisphenol F (DGEBF) and a dimethylaminopropylamine-epoxy adduct. To our knowledge, very few cases of contact dermatitis caused by these constituents have been reported ${ }^{6,7)}$.

\section{Methods}

\section{Production and subjects}

The plant that was investigated manufactures radio communications equipment and a computer system for toll collection. During June-July of 1998, a total of 105 workers took part in the work of protecting important information on a circuit board for a police radio and worked with epoxy coatings. This temporary work included the following processes: (1) filling syringes with one-component epoxy 


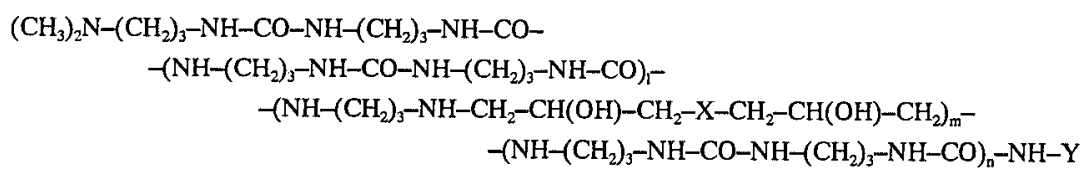

Fig. 1. Chemical structure of an amine-epoxy adduct in two epoxy coatings (TB2202 and TB2206B).

It was impossible to obtain detailed information on the components ( $\mathrm{X}$ and $\mathrm{Y}$ ) of the hardener because its chemical structure is kept secret. coatings; (2) manual application of epoxy coatings using a dispenser; (3) stacking of coated boards; (4) transport of the latter to a curing oven, where the resin dries and polymerizes. The 105 workers were assigned to each of the above activities (filling, coating, and transport).

The following epoxy coatings were used as covering materials: TB2202 (ThreeBond Co., Ltd., Japan) and TB2206B (ThreeBond Co., Ltd., Japan). The front surfaces of the circuit boards were first coated with TB2206B, using a dispenser, and then hardened at a curing oven temperature of $65^{\circ} \mathrm{C}$. Similarly, the back surfaces of the circuit boards were treated with TB2202. Then, the appearance of the circuit boards was examined. The amounts of TB2206B and TB2202 used in a month were about $800 \mathrm{~kg}$ and about 200 $\mathrm{kg}$, respectively.

The subjects consisted of 101 male and 4 female workers, ranging in age from 20 to 51 (mean $\pm \mathrm{SD}, 27.5 \pm 8.2$ ) years. None of the subjects had previous contact with epoxy resins in the workplace. We performed our investigation in July through August of 1998.

\section{Chemical analysis}

According to the material safety data sheet, two epoxy coatings (TB2202 and TB2206B) are DGEBF-based epoxy resins using an amine-epoxy adduct as a hardener. The manufacturer kindly provided us with the white powdery hardener (Fig. 1) and informed us that the amine used for the adduct in the hardener was 3-dimethylaminopropylamine (DMAPA) (Fig. 2). DMAPA is a colorless transparent liquid (b.p. $123^{\circ} \mathrm{C}$ ).

For more information on the allergenicity of the hardener, the amount of the polyamine remnant was analyzed by a Shimadzu GC-17A gas chromatograph with flame ionization detector. The column was a fused silica capillary column (SUPELCO's $\mathrm{DB}^{\mathrm{TM}-1}, 60 \mathrm{~m}$ long $\times 0.32 \mathrm{~mm}$ in inside diameter; film thickness $1 \mu \mathrm{m})$. Column temperature programming involved (1) $80^{\circ} \mathrm{C}$ for $20 \mathrm{~min}$, (2) $300^{\circ} \mathrm{C}\left(40^{\circ} \mathrm{C} /\right.$ min) and (3) $300^{\circ} \mathrm{C}$ for $5 \mathrm{~min}$. As a carrier gas we used nitrogen at $100 \mathrm{kPa}$. The detector temperature was $200^{\circ} \mathrm{C}$.

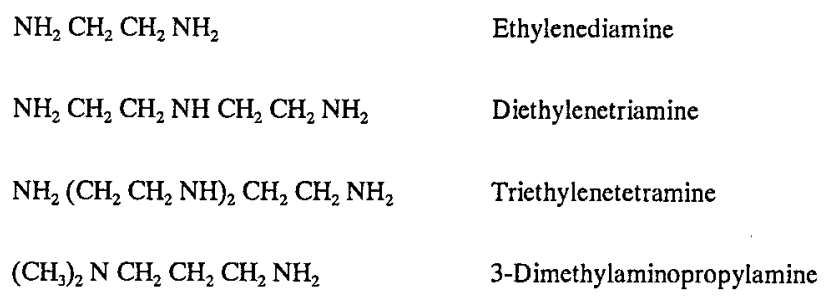

Fig. 2. Structure of aliphatic polyamines.

A sample solution was prepared by dissolving $50 \mathrm{mg}$ of the hardener in $10 \mathrm{ml}$ of isopropyl alcohol (IPA). A standard solution of DMAPA was prepared by adding $0.1 \mathrm{ml}$ of DMAPA to $10 \mathrm{ml}$ of IPA. This solution was then further diluted to appropriate concentrations. Then, a $1.0 \mu \mathrm{l}$ of each sample was injected using a splitless technique at $150^{\circ} \mathrm{C}$. The retention time for DMAPA was $11.5 \mathrm{~min}$.

\section{Medical examination}

All the participants were interviewed about the type of work, working periods, skin contact with epoxy coatings, protective measures, the symptoms of dermatitis, the latent period of dermatitis and the localization, and the influence of certain working conditions on the occurrence of dermatitis. Hands and forearms of all workers were examined for skin disorders, and they were questioned to see whether they began to develop skin symptoms during the work shifts. A case was defined as a person who had a relevant skin disorder on his hands/forearms at the time of examination, or who had experienced recurrent episodes or a single episode of skin disorder on the hands/forearms of at least one week's duration. Patch tests could not be carried out at this time, as informed consent was not obtained from the subjects.

\section{Results and Discussion}

Of 105 workers, 17 (16\%), including 16 men and a woman, their ages ranging from 20 to 25 (mean $\pm \mathrm{SD}, 21.4 \pm 1.8$ ) years, developed dermatitis (itching red papulous skin) from 
the 2 one-component epoxy coatings used in the workplace. The mean period between starting work and the occurrence of dermatitis was 21.5 (range 14-29) days. All the symptomatic workers received medication for dermatitis, indicating that their symptoms were very troublesome. On the other hand, 13 (12\%) had only slight redness and itching on their hands and/or forearms, and their symptoms disappeared in two or three days.

Table 1 shows the affected sites in 17 individuals with work-related dermatitis. The hands were the commonly affected region (13 of 17 cases: $76.5 \%$ ), followed by the forearms $(41.2 \%)$ and wrists $(29.4 \%)$. The upper limb was involved in all of the cases. Jolanki et al. ${ }^{3)}$ have also stated that the hands, forearms and wrists are the typical localizations of skin disorders from exposure to epoxy resin compounds.

The relation between work-related dermatitis and month of starting work, working periods, and activity is shown in Table 2. A significant difference was found in the frequency of work-related dermatitis between the two main activities $(\mathrm{P}<0.05)$. At the time of examination, it was confirmed that

Table 1. Percentage of affected sites in $\mathbf{1 7}$ individuals with work-related dermatitis

\begin{tabular}{lcc}
\hline \multicolumn{1}{c}{ Sites } & Number & $\%$ \\
\hline Hands & 13 & 76.5 \\
Forearms & 7 & 41.2 \\
Wrists & 5 & 29.4 \\
Neck & 4 & 23.5 \\
Face & 4 & 23.5 \\
Trunk & 1 & 5.9 \\
\hline
\end{tabular}

the symptomatic workers often had epoxy coating exposure via skin contact during the coating and filling processes but not exposure to vapour from the ovens. It is highly possible that the symptoms of dermatitis were caused by skin contact with the coatings (direct route) and not by strong exposure to vapour of the coatings (airborne route). Additionally, the duration of skin exposure was significantly longer in the symptomatic subjects than in the nonsymptomatic subjects $(\mathrm{P}<0.005)$. Thus, it was concluded that the frequency and duration of skin contact are important in developing skin symptoms.

There were 17 cases (30\%) in a group of 57 workers (including 2 carriers and 6 foremen) who started work in June. This fact shocked an industrial physician and management staffs from the plant health and safety department. A work site visit was immediately performed; it became evident that the work clothes, tools and benches were always contaminated by epoxy coatings, and that contaminated gloves were used repeatedly. We advised regular cleaning of the work clothes, tools and benches, the proper wearing of protective gloves, and the use of barrier creams. As a result, in July, an automatic system for application of the epoxy coatings was introduced and adequate safety instructions to the workers reinforced. Since then, none of the workers developed symptoms of contact dermatitis. From these results, it is clear that the following multiple protective measures can protect workers from the significant risk of contact dermatitis: education of workers about the major health hazards of epoxy coatings, individual protective devices, and automation of the production methods.

According to the manufacturer, the respective amounts

Table 2. The relation between work-related dermatitis and various factors in a group of 105 workers exposed to epoxy coatings

\begin{tabular}{llcc}
\hline & & \multicolumn{2}{c}{ Exposed workers } \\
\cline { 3 - 4 } & & $\begin{array}{c}\text { Symptomatic } \\
(\mathrm{n}=17)\end{array}$ & $\begin{array}{c}\text { Nonsymptomatic } \\
(\mathrm{n}=88)\end{array}$ \\
\hline month at starting to work & June & $17^{*}$ & 40 \\
with epoxy resins & July & 0 & 48 \\
days at work & $1-10$ days & 0 & 47 \\
& $10-20$ days & $5^{* *}$ & 21 \\
main job & $\geqq 20$ days & $12^{* * *}$ & 20 \\
& coating and/or filling & $17^{\dagger}$ & 70 \\
& transport and/or foremen & 0 & 18 \\
\hline
\end{tabular}

Chi-square test or Fisher's exact test was employed for comparison of the data. *Significant vs July $(\mathrm{p}<0.0001) . * *, * * *$ Significant vs $1-10$ days $(* * \mathrm{p}<0.005, * * * \mathrm{p}<0.0001)$. 'Significant vs transport and/or foremen $(\mathrm{p}<0.05)$. 
Table 3. Amounts of chemical constituents of epoxy coatings used in the workplace

\begin{tabular}{lcc}
\hline \multirow{2}{*}{\multicolumn{1}{c}{ Substance }} & \multicolumn{2}{c}{ Percentage present } \\
\cline { 2 - 3 } & TB2202 & TB2206B \\
\hline DGEBF-based epoxy resin & 79.9 & 72.6 \\
DMAPA-epoxy adduct & 20.0 & 18.0 \\
Filler & - & 8.7 \\
Colorant & 0.1 & 0.7 \\
\hline
\end{tabular}

DGEBF; diglycidyl ether of bisphenol F. DMAPA; 3dimethylaminopropylamine.

of the ingredients in the two epoxy coatings (TB2202 and TB2206B) are shown in Table 3. The epoxy coatings contained $72.6 \%$ to $79.9 \%$ DGEBF-based epoxy resins and $18 \%$ to $20 \%$ hardener. Epoxy resins based on DGEBF have been found to be causes of allergic contact dermatitis ${ }^{6}$. As shown in Fig. 1, the hardener contains a great many secondary and tertiary amino groups and thereby can cause irritant dermatitis, although we found very little information on the allergenicity of the hardener. However, the hardener may act as a contact sensitizer, since it is speculated that the amino groups in the hardener share the same epitope with the terminal groups of ethylenediamine, diethylenetriamine, and triethylenetetramine (Fig. 2) 2-12) $^{8}$.

On the other hand, it was reported that amine-epoxy adducts induced sensitization due to the polyamine remnants, and that the amounts of the free polyamines ranged from about $5 \%$ to about $20 \% \%^{1,4)}$. DMAPA belongs to a group of aliphatic amines, which include the 3 above-mentioned amines (Fig. 2) ${ }^{8-12)}$. On gas chromatographic analysis, we found that the hardener contained about $0.16 \%$ free DMAPA, corresponding to $0.032 \%$ DMAPA in TB2202 and $0.029 \%$ DMAPA in TB2206B. It is unlikely that only trace amounts (less than $0.05 \%$ ) of free DMAPA in the epoxy coatings caused the skin symptoms of the workers. Thus, it is possible that the causes of work-related dermatitis were DGEBFbased epoxy resins and the hardener. In the present study, however, it was impossible to determine the specific agent responsible for the worker's symptoms or to distinguish between allergic and irritant contact dermatitis, because no patch tests were performed.

In conclusion, for occupational hygiene reasons, skin contact with epoxy coatings should be minimized by taking all possible protective measures, including individual protective devices, and by the introduction of automatic production methods. Finally, better instruction of the workers on the potential dangers of epoxy coatings is essential for the prevention of epoxy coating dermatitis.

\section{References}

1) Kanerva L, Joranki R, Estlander $T$ (1991) Allergic contact dermatitis from epoxy resin hardeners. Am J Contact Dermat 2, 88-97.

2) Angelini G, Rigano L, Foti C, Granodolfo M, Vena G, Bonamonte D, Soleo L, Scorpiniti A (1996) Occupational sensitization to epoxy resin and reactive diluents in marble workers. Contact Dermat 35, 11-6.

3) Jolanki R, Kanerva L, Estlander T, Tarvinen K, Keskinen H, Henriks-Eckerman M-L (1990) Occupational dermatoses from epoxy resin componds. Contact Dermat 23, 172-83.

4) Kanerva L, Estrander T, Jolanki T (1996) Occupational allergic contact dermatitis caused by 2, 4, 6-tris(dimethylaminomethyl)phenol, and review of sensitizing epoxy resin hardeners. Int J Dermatol 35, 852-6.

5) Venables KM (1989) Low molecular weight chemicals, hypersensitivity, and direct toxicity: the acid anhydrides. Br J Ind Med 46, 222-32.

6) Ponten A, Bruze M (1999) Occupational allergic contact dermatitis from epoxy resins based on bisphenol $\mathrm{F}$. Contact Dermat 41, 235.

7) Sugai $T$ (1986) Atlas of contact dermatitis, 178-81, Kanehira-Shuppan, Tokyo (in Japanese).

8) Rudzki E, Krajewska D (1976) Cross-reactions between ethylenediamine, diethylenetriamine and triethylenetetramine. Contact Dermat 2, 311-3.

9) Krajewska D, Rudzki E (1976) Sensitivity to epoxy resins and triethylenetetramine. Contact Dermat 2, 1358.

10) Rudzki E (1978) Dermatitis from epoxy resin, triethylenetetramine and ethylenediamine. Contact Dermat 4, 53.

11) Meding B (1982) Allergic contact dermatitis from diethylenetriamine in a goldsmith workshop. Contact Dermat 8, 142.

12) Ormerod $A$, Wakeel R, Mann $T$, Main $R$, Aldridge $R$ (1989) Polyamine sensitization in offshore workers handling drilling muds. Contact Dermat 21, 326-9. 